\title{
PERSPECTIVES DEMOGRÄFIQUES
}

\section{EL FRACÀS ESCOLAR DELS DESCENDENTS DE LA IMMIGRACIÓ A CATALUNYA: MÉS QUE UNAASSIGNATURA PENDENT}

\author{
Jordi Bayona i Andreu Domingo, Centre d'Estudis Demogràfics
}

Els descendents dels immigrats internacionals i la seva integració social han de ser un dels objectius prioritaris per a la construcció de la cohesió social. No obstant, les dades estadístiques disponibles són poques, fragmentàries i clarament insuficients. En aquest número del Perspectives Demogràfiques presentem el perfil demogràfic dels descendents dels immigrats, la seva relació amb la immigració, la diversitat, la distribució territorial i el rendiment escolar, com a eina per a lluitar contra la desigualtat i la discriminació d’un grup poblacional que en el futur proper pot representar més de la quarta part dels joves residents a Catalunya. Els resultats provenen de la recerca efectuada per a la Secretaria d’Igualtat, Migracions i Ciutadania “Resultats escolars, migració iterritori. Catalunya, 2011-2016", i han estat possibles gràcies a l'enllaç entre les dades del Departament d'Ensenyament de la Generalitat de Catalunya dels alumnes del curs 2015-16 i el Registre Estadístic de la Població, realitzada per l’Institut d’Estadística de Catalunya (Idescat).

\section{EL BÉ MÉS PREUAT}

Sens dubte, la contribució més valuosa de la immigració al país de recepció és la seva gent, i encara més els seus descendents amb tot el seu potencial. Coneguts popularment com a "Segona Generació", aquesta població xifrada a Catalunya pel Cens de 2011 en poc més de 183 mil persones -avui encara majoritàriament infantil i juvenil- incorporarà com afegit la pròpia càrrega de diversitat $i$ alhora el paper de pont entre la generació dels seus progenitors i la societat receptora, i entre els països d'origen d'aquests i Catalunya. El creuament dels registres administratius i les estadístiques de població han permès recuperar el lloc de naixement dels progenitors i l'any d'entrada de l'alumne a Catalunya, indispensables per a reconstruir una tipologia d'alumnes en funció del seu estatus migratori.

La figura 1 mostra els alumnes immigrats o descendents d'immigrats a Catalunya en el curs 2015-16 segons el seu "estatus migratori”. Del 1,1 milió d'alumnes matriculats en els nivells educatius no universitaris de règim general i nascuts des de 1998, els alumnes amb antecedents migratoris recents assoleixen una mica més d'una quarta part del total d'alumnes (el 26,2\%). Pel seu anàlisi s'ha utilitzat una nomenclatura per "Generacions". Malgrat que aquestes aproximacions han estat molt criticades, ja que poden crear la sensació que els fills dels immigrats nascuts al país receptor segueixen essent categoritzats incorrectament com a "immigrats", i que així, d'alguna manera contribueixen a estigmatitzar-los, la seva popularització dins i fora de l'acadèmia, i el seu

FIGURA 1. Estatus migratori dels alumnes no autòctons a Catalunya, segons l'any de naixement, curs 2015-16.
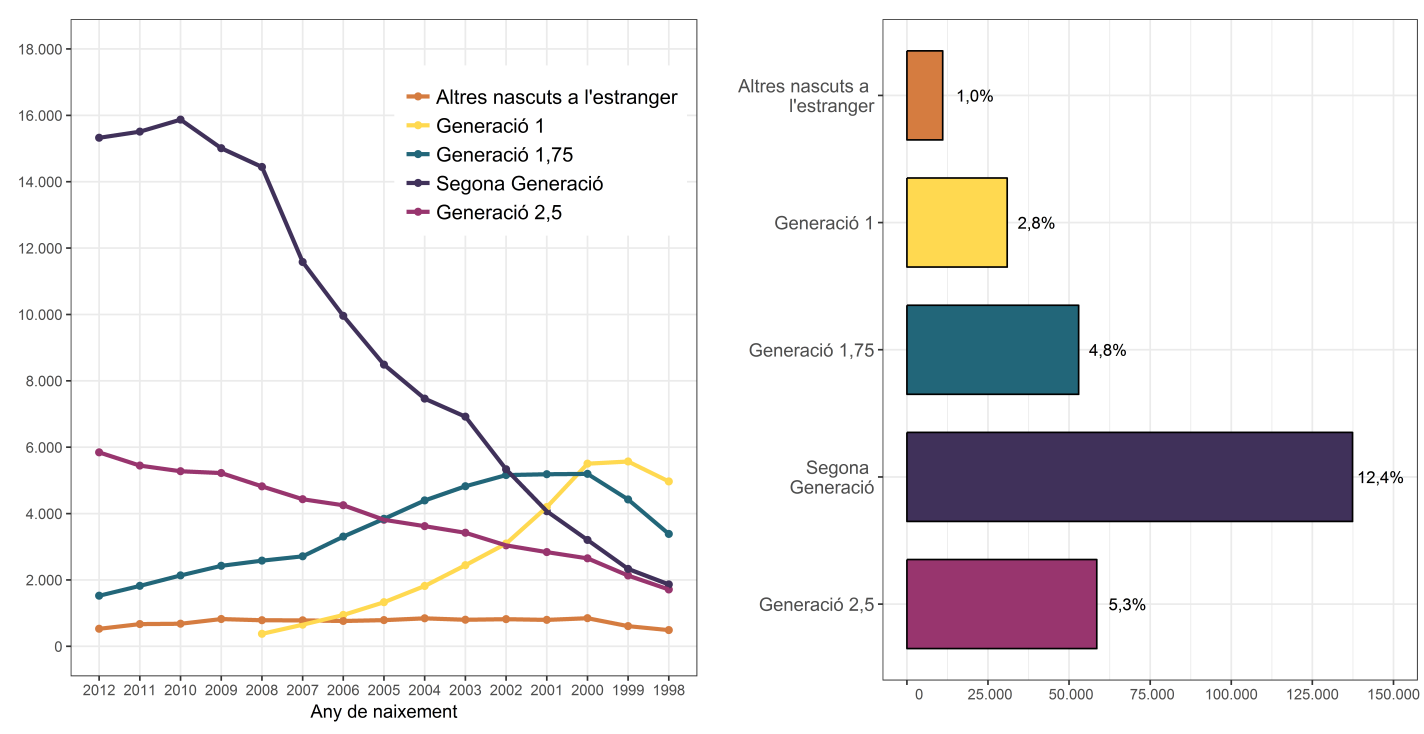

Font: Elaboració pròpia a partir de les dades del Departament d'Ensenyament i l'Idescat. 
poder analític, fa que nosaltres també la utilitzem indistintament amb la definició més ampla de l'estatus de l'infant segons la seva vinculació amb la immigració. Especialment difosa en els estudis sobre la integració escolar dels descendents dels immigrats, nosaltres hem adaptat a la realitat del Sistema escolar català la taxonomia emprada per Ruben Rumbaut (2014). D’aquesta manera la nostra classificació és: 1) Generació 1: aquells alumnes nascuts a l'estranger i que han arribat a Catalunya amb set o més anys, i que per tant no s'hagin incorporat al sistema educatiu des del seu inici; 2) Generació 1,75: els alumnes nascuts a l'estranger, però que hauran arribat a Catalunya amb menys de set anys. Per tant, hauran entrat al sistema educatiu obligatori des del principi; 3) Segona Generació: aquells alumnes nascuts a Espanya però que ambdós progenitors (o un, en cas de disposar sols d'informació d'un dels progenitors) siguin nascuts a l'estranger; 4) Generació 2,5: els alumnes que hagin nascut a Espanya però amb un dels seus dos progenitors que hagi nascut a l'estranger; i, 5) Generació 3 o Autòctons: aquells alumnes que siguin nascuts a Espanya i que els seus progenitors també hi hagin nascut. En cas de tenir informació de sols un dels progenitors, i que aquest hagués nascut a Espanya, també es considerarà l'alumne com a tal.

Segons l'any de naixement s'observa un percentatge decreixent a l'escola de situacions relacionades amb el procés migratori. Entre els més grans, la majoria cursant Batxillerat o Cicles formatius, aquestes circumstàncies afecten el 22,7\% dels alumnes, per un $31,9 \%$ entre els més petits, que es troben en el segon cicle d'Educació Infantil. Però, a més a més del seu pes sobre el conjunt d'alumnes, amb l'evolució per edats es produeix un important canvi en l'estatus migratori. Si entre els alumnes de major edat són la Primera Generació i la Generació 1,75 les més representades, entre els més petits la Segona Generació és majoritària. L'aturada dels fluxos migratoris internacionals relacionada amb la crisi econòmica i la pròpia maduració i antiguitat del procés migratori justifiquen aquesta evolució. Les categories d'alumnes nascuts a l'estranger sumen un 8,5\% del total d'alumnes i són minoritàries entre els primers cursos encara que assoleixen un màxim del 17,2\% entre els nascuts a 1999. Les dues categories d'alumnes nascuts a Espanya representen el 17,6\% dels alumnes, des d'un 6,5\% entre els nascuts a 1998 fins a un 29\% dels alumnes nascuts l'any 2012. Actualment, tres de cada deu alumnes que iniciaren l'escolarització el curs 201516 pertanyien a la Segona Generació o la Generació 2,5. En xifres absolutes, i en les edats considerades, la Segona Generació agrupava el curs 2015-16 a 137.377 alumnes, des dels 1.866 nascuts a 1998 i encara escolaritzats, al màxim de 15.871 nascuts l'any 2010.

Centrem, a partir d'ara, l'atenció en els alumnes de la Segona Generació, ja que es tracta del grup d'alumnes de major volum per darrere dels autòctons, a molta distància de les altres situacions, i que al mateix temps coneixerà el creixement més intens en els propers anys, essent gradualment la situació relacionada amb la immigració majoritària a les aules del país. La distància existent en el rendiment escolar entre els alumnes autòctons i els de la Segona Generació ens servirà també per mesurar les desigualtats existents entre els fills dels immigrants.

FIGURA 2. Principals orígens dels alumnes de Segona Generació i distribució territorial a escala municipal a Catalunya, curs 2015-16
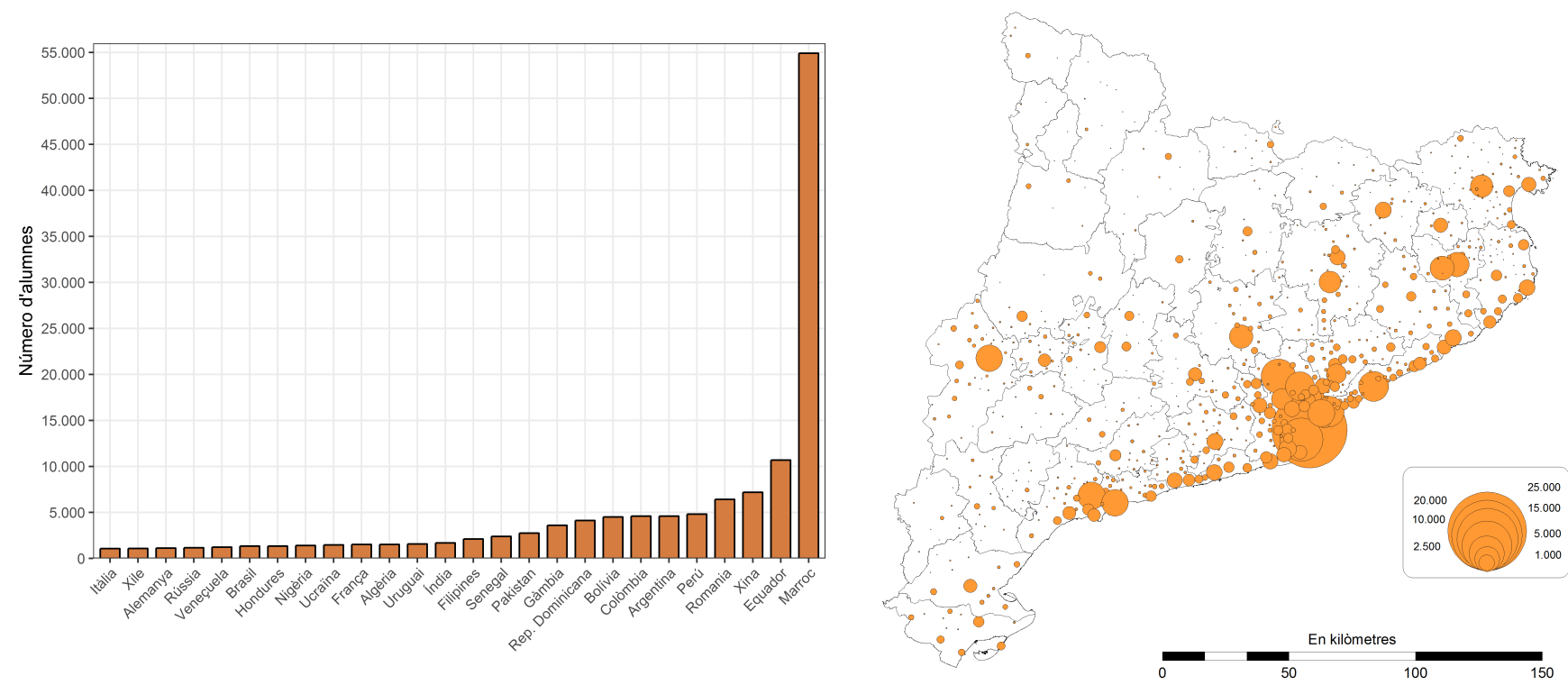

Font: Elaboració pròpia amb dades del Departament d'Ensenyament i Idescat. 


\section{DIVERSITAT I DISTRIBUCIÓ TERRITORIAL}

La figura 2 representa els 26 orígens amb més d'un miler d'alumnes pertanyents a la Segona Generació. Quatre de cada deu casos són d'origen marroquí, superant els cinquanta mil alumnes, situació que és conseqüència de l'antiguitat de les migracions del Marroc a Catalunya i de la seva estructura familiar. En la resta d'orígens existeix una major dispersió, amb els alumnes d'origen equatorià com a segon origen, superant els 10 mil alumnes. Per sobre dels cinc mil trobem també a xinesos i romanesos. D’aquesta manera, els quatre primers orígens entre els alumnes de Segona Generació pertanyen a continents diferents, mostrant l'alta diversitat de la migració internacional rebuda a Catalunya. Fins a 22 orígens més superen el miler d'alumnes en la Segona Generació. En la seva distribució territorial, en xifres absolutes s'observa la seva alta presència als municipis de la Regió Metropolitana de Barcelona, però igualment a tots els municipis litorals i les ciutats de Lleida i Girona. Destaquen també les capitals comarcals interiors, com Manresa o Vic. Malgrat que representen un 12,4\% dels alumnes, en alguns municipis s'assoleixen percentatges molt més elevats, més encara si tenim en compte que en els ensenyaments inicials aquests valors són molt superiors, per exemple a Salt (el 47\%), Castelló d'Empúries (33\%), Manlleu (30\%), Guissona (29\%) o Palafrugell (28,7\%). Entre els municipis amb major nombre d'alumnes, a l'Hospitalet de Llobregat (el 23,1\%), Mataró (18,8\%) o Santa Coloma de Gramenet $(18,3 \%)$ és on la presència de la Segona Generació resulta més notòria.

\section{RENDIMENT ESCOLAR}

El rendiment escolar dels alumnes es pot mesurar de vàries maneres. En el nostre cas, es compta amb les dades d'assoliment del Grau d'ESO dels alumnes matriculats a quart d'ESO en escoles públiques a Catalunya. El no assoliment d'aquest títol és el que porta a parlar, a escala internacional, de fracàs escolar. En les escoles públiques catalanes hi trobem 42.687 alumnes, el 61,9\% de tots els alumnes d'aquest curs, i amb una sobrerepresentació d'aquells relacionats amb la immigració, amb 12.976 alumnes (el 30,4\% dels alumnes). En la composició per orígens d'aquests alumnes la Primera Generació és molt important (6.168 alumnes), també la Generació 1,75 (5.041 alumnes), mentre que la Segona Generació o la Generació 2,5 són situacions encara emergents (2.928 i 2.640 alumnes respectivament).

La taula 1 ens mostra el percentatge d'alumnes que no assoleixen el Grau d'ESO en el curs 2015-16 segons l'estatus migratori i diferenciant entre sexes. La no superació del Grau en el curs analitzat no significa que aquest títol no es pugui aconseguir amb posterioritat. Per altra banda, les dades fan referència a alumnes matriculats amb 18 o menys anys, i poden subestimar el fracàs ja que els alumnes que abandonen l'ESO abans d'arribar al quart curs no s'han pogut recuperar. La pertorbació migratòria es mostra com el primer factor que explica en conjunt el rendiment escolar: l'arribada tardana, la discontinuïtat $i$, per suposat, l'abandonament marcaran els resultats més negatius dels infants. És així com les generacions més afectades per la immigració (1 i 1,75) solen obtenir pitjors resultats que els ja nascuts a Catalunya. Moltes de les variacions per origen es deuran a estratègies migratòries marcades per aquest factor -especialment la discontinuïtat en les segones generacions-.

En relació als alumnes autòctons, la Generació 2,5 (amb un dels progenitors nascut a Espanya i l'altre a l'estranger) no mostra diferències significatives en els resultats aconseguits. En canvi, en la resta de situacions, augmenta i molt el fracàs escolar. Els nois de la Segona Generació presenten percentatges de fracàs escolar vuit punts superiors als alumnes autòctons, i sis punts entre les noies, que gairebé dupliquen el fracàs escolar de les alumnes autòctones. Els alumnes nascuts a l'estranger però arribats a Catalunya de ben petits (la Generació 1,75), mostren resultats molt similars a la Segona Generació, i que ens permeten afirmar que l'entrada al sistema escolar des d'un inici no els diferencia dels fills d'immigrants nascuts a Catalunya. Els valors de fracàs escolar més elevats es donen entre els alumnes de Primera Generació, arribats amb més de set anys, on una tercera part dels nois i una quarta part de les noies no assoleixen el títol. Aquestes xifres moltes vegades s'expliquen per una arribada recent, on en molts casos l'escola sols és el pas intermedi per la futura inserció en el mercat laboral.

Si ens fixem en els alumnes de Segona Generació segons l'origen, el baix nombre de casos fa que per a la majoria d'orígens els valors obtinguts no siguin representatius. Si agreguem els alumnes per continent d'origen dels progenitors, el fracàs seria menor entre els

TAULA 1: Percentatge d'alumnes d'escoles públiques que no assoleixen el Grau d'ESO, per sexe i estatus migratori, Catalunya, curs 2015-16.

\begin{tabular}{lrrr} 
& Homes & Dones & Total \\
Autòctons & 13,2 & 7,3 & 10,3 \\
Generació 2,5 & 12,5 & 7,7 & 10,1 \\
Segona Generació & 21,2 & 13,7 & 17,3 \\
Generació 1,75 & 21,7 & 12,2 & 16,7 \\
Generació 1 & 34,6 & 23,5 & 29,2 \\
Total alumnes & $\mathbf{1 7 , 4}$ & $\mathbf{1 0 , 4}$ & $\mathbf{1 3 , 9}$ \\
\hline
\end{tabular}

Font: Elaboració pròpia amb dades del Departament d'Ensenyament i Idescat. 
d'origen europeu $(11,3 \%)$ i americà $(15,5 \%)$, on la condició socioeconòmica dels primers i la proximitat a l'idioma dels segons justificarien els millors resultats. Pel conglomerat asiàtic el fracàs ascendeix al 17,8\% (sense diferències entre sexes), tot i que cal considerar la gran variabilitat d'aquest bloc, amb resultats molt allunyats entre xinesos (13,6\%), filipins (21,9\%) i pakistanesos (35\%) per exemple, per només esmentar els tres grups principals. A la cua, amb el 19,2\% entre els alumnes, trobem els d'origen africà. En aquest darrer cas el 15,9\% de fracàs escolar entre els alumnes marroquins és preocupant tractant-se del primer origen, especialment si tenim en compte el creixement d'aquest grup en un futur immediat. Però és encara més preocupant el 40,9\% de no assoliment del grau entre els alumnes d'origen gambià (segon origen en nombre d'alumnes de Segona Generació a quart d'ESO), que fins i tot ascendeix al 54\% entre els nois (valor minimitzat per un possible abandonament abans de finalitzar l'ESO), i que deixa entreveure el fracàs del sistema educatiu amb alguns orígens determinats, $\mathrm{i}$ les dificultats futures que aquests joves poden tenir en la seva inclusió i posterior progressió en el món laboral.

\section{EN NOM DE LA COHESIÓ SOCIAL}

L'èxit o el fracàs dels descendents dels immigrats constitueix la pedra de toc de l'èxit o el fracàs de la nostra societat en el futur. Allò que anomenem cohesió social (si ens referim prioritàriament a les classes socials) i cohesió comunitària (si prioritzem la diversitat etnocultural) en el futur (Cantle, 2005), és a dir, el sentiment de pertinença compartida i confiança mútua de la comunitat que formen els que resideixen en un mateix territori, més enllà de la seva classe social i la diversitat etnocultural o religiosa, correspondrà a la integració social i intercultural de la població.

Malgrat els indubtables esforços del Sistema educatiu que s'han donat en els anys passats -en un context d'austeritat-, els nivells de fracàs escolar mesurats per l'obtenció del grau d'ESO, i la distància que els separa dels resultats de la població autòctona són insostenibles. Cal una actuació especial i urgent sobre la matèria. La selecció negativa d'alguns dels orígens dels descendents dels immigrats apunta a una intolerable racialització del fracàs escolar, amb tot el que comporta de llosa tant sobre l'evolució de les trajectòries individuals dels que avui són adolescents com de fractura en la societat catalana. Hi ha canvis estructurals que s'han d'abordar amb la implicació no només de la comunitat educativa, o la d'altres departaments del govern, a part òbviament del Departament d'Ensenyament i la Secretaria d'Igualtat, Migracions i Ciutadania, sinó del conjunt de la societat. Per començar amb la disponibilitat de dades acurades que permetin la identificació i seguiment d'aquesta població de forma sistemàtica. Cal plantejar-se accions de xoc a curt $\mathrm{i}$ a mig termini per lluitar contra la desigualtat independentment de l'origen de l'alumnat, però també s'haurà de sospesar la inclusió de mesures de discriminació positiva dels col-lectius més afectats, no només sobre els alumnes, sinó sobre l'entorn comunitari i territorial on resideixen aquests infants i on s'ubiquen els centres escolars.
Referències bibliogràfiques

Albaigés, Bernat i Ferrer-Esteban, Gerard (2017) L'estat de l'educació a Catalunya. Anuari 2016. Indicadors sobre l'èxit educatiu a Catalunya. Fundació Jaume Bofill.

Cantle, Ted (2005) Community Cohesion: A New Framework for Race and Diversity. Londres: Palgrave Macmillan.

Portes, Alejandro; Aparicio, Rosa i Haller, William (2016) Spanish Legacies: The Coming of Age of the Second Generation. Oakland, California: University of California Press.

Rumbaut, Ruben (2014) "Ages, Life Stages, and Generational Cohorts: Decomposing the Immigrant First and Second Generations in the United States". International Migration Review, 38 (2): 1160-1205.
Cita

Jordi Bayona i Andreu Domingo (2018) "El fracàs escolar dels descendents de la immigració a Catalunya: més que una assignatura pendent", Perspectives Demogràfiques, 11: 1-4.

Editors

Andreu Domingo i Albert Esteve

Correspondència dirigida $a$

Jordi Bayona

jbayona@ced.uab.cat

Crèdits

Gràfics: Anna Turu

Maquetació: Xavier Ruiz Vilchez
Agraiiments

Al Departament d'Ensenyament i a l'Institut d'Estadística de Catalunya (Idescat), que han proporcionat les dades necessàries per aquest exercici.

Enllaç url

http://ced.uab.es/difusio/butlleti-perspectives-demografiques
Contacte

Centre d'Estudis Demogràfics. Carrer de Ca n’Altayó, Edifici E2 Universitat Autònoma de Barcelona o8193 Bellaterra / Barcelona Espanya

Telèfon: +34 935813060

Correu:demog@ced.uab.es Web: http://ced.uab.es/ 